\title{
A TRAJETÓRIA DE UMA PARTEIRA DO ARQUIPÉLAGO DO MARAJÓ
}

\section{THE PATH OF A PARTY OF THE ARCHIPELAGO OF MARAJÓ}

Denise Machado CARDOSO ${ }^{1}$

Universidade Federal do Pará-UFPA

José da Silva RIBEIRO

Universidade Aberta - UAB - Portugal

\begin{abstract}
Resumo: Os conhecimentos das parteiras são adquiridos de maneira tradicional e remetem às suas ancestralidades. No município de Melgaço, arquipélago do Marajó, Amazônia Brasileira, essa atividade possui relevância e garante práticas mais humanizadas durante o nascimento. A pesquisa sobre Maria da Silva, uma dessas parteiras, objetiva investigar sua trajetória e foi baseada na oralidade, na etnografia. A investigação de campo permitiu evidenciar que essas práticas se mantêm devido à maneira como parto é assistido, proporcionando protagonismo à parturiente.
\end{abstract}

Palavras-chave: Marajó. Parteiras tradicionais. Oralidade. Saberes Ancestrais.

\begin{abstract}
Midwives' knowledge is acquired in a traditional way and refers to their ancestry. In the municipality of Melgaço, Marajó archipelago, Brazilian Amazon, this activity has relevance and guarantees more humanized practices during the birth. The research on Maria da Silva, one of these midwives, objective aims to investigate its trajectory and was based on orality and the ethnography. Field research has shown that these practices are maintained due to the way in which birth is assisted, providing protagonism to the birthing woman
\end{abstract}

Keywords: Marajó. Traditional midwives. Orality. Ancestral Knowlegde.

\footnotetext{
${ }^{1}$ Doutora em Desenvolvimento Socioambiental (NAEA-UFPA). Professora da Universidade Federal do Pará. Coordena o Grupo de Estudos sobre Antropologia Visual e da Imagem (VISAGEM) e o Grupo de Pesquisa sobre Populações Indígenas 'Eneida Correa de Assis' (GEPI). Atua como Assessora Adjunta na Assessoria da Diversidade e Inclusão Social (ADIS-UFPA) e é membro do Comitê de Antropologia Visual da Associação Brasileira de Antropologia (CAV-ABA): denisecardosoufpa@gmail.com

${ }^{2}$ Doutor em Ciências Sociais-Antropologia pela Universidade Aberta de Portugal. Professor visitante da Universidade Mackenzie (Educação, Arte e História da Cultura), Universidade de Múrcia - Espanha (ERASMUS) e da Universidade de Savoie - França. Coordena o Grupo de Investigação antropologia visual /media e mediações culturais - CEMRI: Universidade Aberta: jsribeiro.49@gmail.com
} 


\section{Introdução}

As atividades desenvolvidas por parteiras são importantes na saúde reprodutiva de mulheres. O oficio de partejar é milenar e se mantem como relevante ainda nos dias atuais, pois contribui para o bem-estar e bem viver de mulheres em diferentes sociedades. No arquipélago do Marajó, região Norte do Brasil, as parteiras têm se destacado ao longo dos anos e perpetuam conhecimentos sobre a reprodução humana para além da medicina considerada oficial.

Nesta pesquisa sobre a trajetória de Maria da Silva, uma das mais antigas parteiras de Melgaço, município localizado no arquipélago do Marajó ${ }^{3}$, realizamos um estudo que enfatiza fontes históricas não convencionais, como é o caso de memórias de pessoas ou de grupos sociais. A pesquisa bibliográfica também foi importante na condução desta investigação sobre o oficio de parteiras, inspirados na compreensão e inclusão de conhecimentos ancestrais sobre o ato de partejar e os desafios desse oficio em tempos atuais e pretéritos. Assim, desenvolvemos uma pesquisa pautada na valorização de conhecimentos outros além daqueles consolidados no âmbito acadêmico.

A pesquisa de campo contou com o suporte metodológico da Antropologia, pois utilizamos a etnografia como uma ferramenta para subsidiar o diálogo etnográfico (RIBEIRO, 2005). Como procedimento metodológico exploramos, ainda, a História Oral a partir dos relatos orais como fonte desta pesquisa por considerar que estes são, dentre outras fontes não convencionais, elementos relevantes para questionar uma visão monocultural da memória.

As conversas informais e entrevistas semiestruturadas se apresentaram com uma oportunidade de diálogo profícuo. E tal como indicado por Ana Canen e Libânia Xavier (2000), os relatos orais são uma importante forma de valorização da diversidade social, de gênero, e de outras culturas na construção de uma memória mais ampla, ou seja, uma perspectiva intercultural crítica.

Gayatri Spivak (2010) também emerge como importante inspiração no trato metodológico, pois apresenta o questionamento se subalternos e subalternas podem falar, ela reitera aquilo que os estudos atuais sobre as regiões antes colonizadas, e em outras ainda marcadas por conflitos de classe, estão buscando conquistar. Para além da hegemonia dos saberes, propõem-se novas epistemologias, novas abordagens, outras perspectivas, e outros saberes.

\footnotetext{
${ }^{3} \mathrm{O}$ arquipélago do Marajó está localizado no estado do Pará e é formado por duas microrregiões: a região do Arari, que comporta os municípios de Cachoeira do Arari, Chaves, Muaná, Ponta de Pedras, Salvaterra, Santa Cruz do Arari e Soure; e a região do Furo de Breves, a qual compreende aos municípios de Afuá, Anajás, Breves, Curralinho, São Sebastião da Boa Vista e Gurupá.
} 
Neste estudo em particular, propusemos instigar discussões sobre o partejar, enfatizando-se a perspectiva de uma mulher parteira, seus costumes, saberes e fazeres. A partir das narrativas sobre sua trajetória de vida desta mulher apresentamos suas experiências e memórias que se cruzam, criando laços que atravessam gerações. Na medida em que o fazer dessa parteira traz novas vidas ao mundo, conta a história de um povo, reforça suas crenças, expõe suas emoções, define relações sociais e reafirma a identidade sociocultural coletiva, e suas narrativas se tornam importantes elementos para a compreensão de seu próprio grupo social.

Procuramos responder às seguintes indagações: O que uma mulher de grupo subalternizado tem a dizer para a academia? De que maneira podemos aprender com mulheres parteiras? Como se dá a interface entre conhecimentos destas mulheres e aqueles da chamada Medicina Oficial? A partir da trajetória de Dona Maria da Silva, quais desafios as parteiras enfrentaram, e enfrentam, no exercício de seus trabalhos? Ainda, cabe enunciar a importância de compreender como elas veem a si mesmas e como outras pessoas envolvidas (direta ou indiretamente) nos processos de partejar as veem. Por certo, a pesquisa de cunho qualitativo anuncia-se como uma adequada estratégia de investigação, pois nos permite levantar questões que não dizem respeito apenas à trajetória de Dona Maria.

O artigo está estruturado em três partes: na primeira apresentamos considerações teóricas sobre memória e suas múltiplas dimensões, enfatizando a memória e suas implicações entre lembranças e esquecimentos. Apresentamos a escolha para navegarmos por rios da Amazônia para realizar o que fora proposto como projeto de pesquisa e de extensão em Melgaço. Em seguida apresentamos a trajetória de Dona Maria ao longo de sua vida em diversos municípios da região do Marajó, e seus relatos sobre suas experiências como parteira nesta região. E concluímos com considerações finais sobre os diálogos estabelecidos com Dona Maria da Silva.

Apresentamos neste artigo alguns elementos biográficos dessa mulher e seus conhecimentos acerca do ato de partejar, sua vivência nos cuidados tradicionais com a saúde da mulher e suas interfaces com a chamada medicina oficial. Embora já tivéssemos um roteiro pré-definido, dialogamos com Dona Maria a cada dia de encontro sobre o que seria tratado naquelas tardes chuvosas, com conversas na cozinha de sua casa e regadas ao sabor de seu café acompanhado de bolo. 


\section{Os caminhos que nos levaram a Melgaço, no arquipélago do Marajó}

A escolha pelo município de Melgaço para desenvolver projeto pesquisa e de projeto de extensão se deu a partir da junção de alguns fatores. Um deles era o fato de haver em Melgaço de Portugal um festival anual de cinema e, por isso, pensou-se em proporcionarmos uma aproximação entre gestores, instituições e moradores destes municípios homônimos a partir da produção fílmica.

O projeto de pesquisa sobre parteiras surgiu como um subprojeto do Projeto de Extensão “Incursões Etnográficas em Melgaço do Marajó-Amazônia Brasileira”. Esse projeto de extensão era voltado para práticas além muros das universidades, e consistiu em oferecer ao grande público aquilo que é produzido no âmbito acadêmico. Ele foi elaborado a partir do interesse em consolidarmos parceria entre equipe de docentes e discentes da Universidade Federal de Goiás e da Universidade Federal do Pará. O objetivo central nesse projeto era o de realizar oficinas de audiovisual com jovens e crianças, para a produção de filmes com a utilização de câmeras fotográficas e telefones celulares. Além disso, promovemos a I e II Mostra de Cinema Juvenil e produção de documentários sobre pessoas de destaque no município, a partir de suas práticas e saberes, respectivamente nos anos de 2019 e 2020.

Desenvolvemos como subprojeto a investigação sobre trajetórias de vida, sempre incorporando o uso da Antropologia Visual, pois na pesquisa de campo com a utilização de imagem, ela se apresenta tanto como um produto de pesquisa quanto um meio para a elaboração de informações feitas a partir da investigação. Aos usos da etnografia, na qual se destacam as conversas informais e a observação direta; somaram-se o registro fotográfico e audiovisual, e todo o processo subsequente de edição.

Além dos procedimentos da Antropologia utilizamos aqueles inerentes à História Oral porque a partir da oralidade, e de outras expressões, seria possível termos acesso às narrativas sobre a trajetória de Dona Maria por ela mesma. Cabe destacar que segundo Maria de Lourdes Janotti e Ricardo de Paula (1988), na História Oral a memória é trazida pelos relatos orais e envolve uma carga emocional forte que interfere na narrativa e na sua interpretação. Desse modo, a subjetividade presente nesses relatos permite perceber valores, crenças e tradições. Consequentemente, as memórias acessíveis de Dona Maria muito nos dizem sobre as memórias de si, entremeadas com aquelas que se consideram como de toda a coletividade.

Ainda sobre os procedimentos relativos à Antropologia, o interesse em produzir um documentário sobre a trajetória de vida de uma parteira, reconhecidamente importante para o município, foi iniciado em 2018 na oportunidade em que conversamos com lideranças locais e nessas 
oportunidades muito se falou sobre as mulheres que realizam acompanham outras mulheres no partejar. Nesse contexto, percebemos o potencial de registro fílmico dos relatos orais realizados a partir de conversas informais desta importante parteira que vive em Melgaço, no arquipélago marajoara.

Sobre o local da pesquisa, pode-se afirmar que Melgaço é um município que se caracteriza por apresentar um ambiente natural marcado pela influência de seus rios e florestas na dinâmica de quem nele vive. Localizado no Arquipélago do Marajó, tem população estimada de 26.642 habitantes, segundo o Instituto Brasileiro de Geografia e Estatística (IBGE), no ano de 2016. Considerando a situação de pobreza, e o difícil acesso à sede/cidade, que atualmente detém um baixo Índice de Desenvolvimento Humano (IDH), as condições de saúde e assistência ao parto levam à criação de alternativas aos métodos institucionalizados de saúde. Neste cenário, as parteiras são elemento fundamental na assistência ao parto, embora outros motivos marcam a opção por estas mulheres pela parturiente.

No ano 2000 o Ministério da Saúde cria o Programa Trabalhando com Parteiras Tradicionais, buscando valorizar os saberes e práticas tradicionais e caracterizar a sua formação e o conhecimento que elas já detêm, considerando as especificidades étnicas e culturais, e articulando seus saberes com o saber científico.

Nesse contexto, a pesquisa sobre a trajetória de vida de Maria da Silva e a produção de um documentário com essa temática são maneiras de valorizar os fazeres e histórias de vida das parteiras de Melgaço (Pará). A partir desse estudo com Dona Maria, registra-se a importância dessas mulheres para as comunidades onde vivem, as relações, laços e conflitos que permeiam o ato de partejar.

Os artefatos para o registro fílmico, as câmeras fotográficas e o recurso para captação de som durante nossas conversas, pouco inibiram as narrativas apresentadas. Ao que tudo indica, tornou-se uma situação de partilha e de estarmos juntos na construção de conhecimento; de melhor aprendizagem sobre a reprodução humana, contracepção, nascimento e os cuidados com a vida; de troca de saberes locais, populares com saberes institucionais - da academia, das instituições de saúde.

Ressaltamos, ainda, que a memória de Dona Maria entrelaçada com aquelas de sua família, e em especial de seu esposo, exigiu o tratamento pela perspectiva de que as lembranças dizem respeito ao grupo ao qual haja pertencimento, ou seja, a memória como algo coletivo, tal como indicado por Halbwachs (2003). As conversas foram a oportunidade de trazer à tona as lembranças de um tempo, de uma trajetória, e de uma sociedade marajoara que ressignifica seus conhecimentos em práticas atualizadas tradicionalmente. 
A memória coletiva se expressa como um aspecto relevante da sociedade desta parte do arquipélago do Marajó, mas não se restringe a esse espaço geográfico porque traz elementos culturais dos modos de vida dos povos e populações ribeirinhas da região Amazônica.

\section{3 "Pra começo de conversa": Memórias de uma mulher que cuida de mulheres}

A proposta de trabalhar com narrativas de parteiras, implica em considerar as suas memórias, com lembranças e com seus esquecimentos, com as memórias individuais que revelam condições de coletividade, uma memória histórica do grupo ao qual estão inseridas, tal como evidenciado por Maurice Halbwachs (2003). Assim o percurso metodológico indicado para este estudo envolve, em muitos casos, o que fora indicado por Vânia Cardoso (2012) em termos de estudos sobre biografias.

Para esta autora, o contar estórias não se refere apenas à produção de conhecimento como um possível acúmulo de dados. Ao contrário, ocorre algo dinâmico, posto que o fazer e o refazer vão sendo incorporados ao longo das narrativas. Assim, contar estórias de si ou de outrem, é um reelaborar e ressignificar fatos e situações, conforme as lembranças vão sendo acionadas e expressas. Desse modo, cabe destacar a perspectiva indicada por Catherine Walsh (2000) na qual

Alenta novos processos, práticas e estratégias de intervenção intelectual que poderiam incluir, entre outras, a revitalização, revalorização e aplicação dos saberes ancestrais, não como algo ligado a uma localidade e temporalidade do passado, mas como conhecimento que tem contemporaneidade para criticamente ler o mundo e para compreender, (re) aprender e atuar no presente (WALSH, 2000, p. 12)

Propomos assim, buscar a compreensão acerca do modo de atuação e percepção de uma parteira sobre o partejar.

Os estudos sobre mulheres parteiras são significativos em diferentes áreas de estudo. Tal produção indica, por exemplo, que as transformações na prática do partejar foram ocorrendo devido ao avanço da chamada medicina convencional, e impactou não apenas nas práticas relativas ao parto, como também nas representações e visões que se tem acerca das mulheres parteiras. Interessante notar, também, que os estudos que tratam dessas dinâmicas foram realizados pela História, pela Medicina, pela Demografia, pela Enfermagem e pela Antropologia, reforçando a relevância do tema no âmbito da pesquisa científica.

Imbuídos pelo interesse em pesquisar os conhecimentos ancestrais de parteiras organizamos uma proposta de estudo que envolvesse, predominantemente as memórias de parteiras, pois o partejar é algo interessante tanto em termos de estudos históricos e sócio antropológicos, estudos da área de 
saúde sobre práticas de cuidados corpóreos, além das pesquisas e propostas no âmbito de políticas públicas sobre saúde em seus vários aspectos.

A obra de Soraya Fleischer (2011) produzida a partir de sua pesquisa antropológica na região do arquipélago do Marajó, e a de Joana Pedro (2003) subsidiaram a pesquisa bibliográfica em nosso projeto. Destacamos que o trabalho de Joana Pedro (2003), embora trate da questão do parto no contexto do silenciamento e rapidez no processo devido à gravidez indesejada no Brasil (início do século XX), traz o debate sobre contracepção, aborto e infanticídio a partir de estudos documentais referentes a este período. O trabalho de Emily Martin (2006) em Maryland, nos Estados Unidos, também é um dos incentivadores para a realização desta pesquisa, pois tal como havíamos proposto ela enfatiza a visão de uma mulher parteira, na medida em que seus estudos indicam a relação do parto com resistência, raça e classe social.

O contato inicial com Dona Maria da Silva ocorreu no ano de 2018 quando planejamos o projeto de pesquisa sobre conhecimentos de mulheres e acerca dos cuidados com saúde e suas bases em conhecimentos ancestrais. Precisamente, iniciamos a investigação no arquipélago do Marajó, no município de Melgaço. A partir de indicação de Izaias Correa Guedes (assessor da prefeitura deste município). Como estávamos interessados em produzir um vídeo sobre o trabalho de parteiras ele nos levou até a casa de Dona Maria e começamos nossa pesquisa utilizando, predominantemente, procedimentos da História Oral, sem deixarmos de lado as práticas etnográficas desenvolvidas em outros estudos. $\mathrm{O}$ interesse em conhecer mais sobre sua biografia foi crescendo ao longo dos meses seguintes até se transformar em projeto de pesquisa mais consistente.

Após o primeiro contato em 2018, retornamos a Melgaço em 2019 com o objetivo de retomar o contato e desenvolver o projeto da biografia, dentre outros temas. O reencontro ocorreu novamente em sua casa quando a procuramos com a proposta de desenvolver um trabalho sobre sua vida. Animados diante do aceite de Dona Maria, passamos a frequentar sua casa para as conversas consigo, além de observar sua vivencia cotidiana como parteira.

As conversas ocorriam sempre à tarde, na cozinha de sua casa, e durante esses momentos era ela quem estabelecia o que seria tratado naquele dia. Ao término desses encontros diários tomávamos café juntas com a equipe da pesquisa e com seus familiares. Em certas ocasiões ele mostrava fotografias, material técnico, documentos, contribuindo para o fluir das respostas que nos dava diante de nossa curiosidade acadêmica, mesclada com curiosidade pessoal, sobre a vida desta mulher.

O que se segue são alguns aspectos dessa pesquisa, cujo projeto é intitulado "Parteiras: práticas e saberes". Em sua trajetória há vários elementos que indicam o modo de vida ribeirinho da região amazônica, em especial das pessoas que vivem nos municípios do Marajó. 


\section{Dona Maria da Silva, trajetória de vida}

Nascida no município de Afuá, também no Marajó, Maria da Silva tem oitenta e quatro anos de idade e está casada, atualmente, com Gerônimo (oitenta e oito anos). Criada pela avó materna, pois ficou órfã ainda cedo, trabalhou desde os onze anos na extração de madeira e fabricação de dormentes ${ }^{4}$. Já adulta, passou a trabalhar com extração do látex de borracha das inúmeras seringueiras (Hevea brasiliensis) desta região. Além disso, extraía o leite de Açacu (Hura crepitans), atividade que quase a deixou cega. Posteriormente, passou a atuar na extração de palmito da palmeira de açaizeiro (Euterpe oleracea). Durante longos anos esteve ligada ao que ela denomina como "trabalho com madeira", seja extraindo as resinas ou com recursos madeiráveis.

Ainda jovem casou e teve onze filhos, mas, desses, quatro faleceram e ficaram três filhas e quatro filhos. Apenas um mora distante, pois mudou-se para Santana, no Amapá (Estado vizinho do Pará). Os demais filhos moram em Melgaço ou em municípios vizinhos. Para Dona Maria, todos querem ficar perto, mas se vão por que precisam trabalhar. Eles são muito "agarrados" à mãe, confidenciou-nos, e o mesmo se observa com seus netos e netas, e bisnetas, sempre em visita à sua casa.

Dona Maria conta de suas dificuldades e desafios para criar os filhos, pois seu primeiro esposo era aleijado de uma perna e se movia com dificuldades. Devido à essa deficiência ela diz que ele pouco auxiliava na criação dos filhos, seja na obtenção de renda ou nos cuidados com a casa e com as crianças. Ela assim descreve a situação: "Ele não trabalhava como eu. Eu saia e levava as crianças pequenas comigo para o mato".

Após seu falecimento, ela ficou viúva por alguns anos até conhecer seu atual marido. Nesse interim, embora diminuíssem as dificuldades financeiras e seu trabalho nas atividades extrativistas nas florestas ficassem cada vez mais esparsos, o "trabalho na roça" com atividades de cultivo de mandioca (Manihot utilisima) e diversas frutas foi mantido ao longo dos anos.

É importante salientar que em suas lembranças desde os tempos de sua infância, passando pelos momentos de seu primeiro casamento, o que Dona Maria traz de modo mais enfático é a superação diante dos desafios e dificuldades por ela enfrentados. Em alguns momentos de nossas conversas ocorridas em 2018, Dona Maria verbaliza a satisfação em ter criado seus filhos e hoje ter uma vida mais tranquila e confortável. Segundo nos relatou:

\footnotetext{
${ }^{4}$ Cada uma das peças de madeira, de metal ou de cimento armado, colocadas no solo, perpendicularmente à via férrea, e em cima das quais são fixados os trilhos.
} 
Hoje tenho sandálias para calçar, tenho rede para dormir, tenho comida na panela. Mas, antes, quando era criança, andava descalça porque não tinha um par de chinelos para calçar, não tinha roupas porque antes tinha que comprar tecido e mandar fazer na costureira.

Ela reflete sobre o momento atual seguindo um raciocínio baseado na comparação entre o ontem e o hoje. E explica que há mais facilidade para comprar as coisas de casa e para si. O tempo anterior, de sua infância e juventude, foi aquele marcado pelas dificuldades não apenas para si, mas para praticamente todas as pessoas pobres. Com isso, ela nos permite refletir sobre processos de dinâmica social, e principalmente sobre níveis diferenciados de pobreza.

A História Oral se apresentou como um importante instrumento nesses momentos da pesquisa porque ela se utiliza de uma metodologia que enfatiza a memória (FREITAS, 2002). Ao observarmos o diálogo com Dona Maria, notamos que o que é trazido oralmente não segue a ordem cronológica e não se refere somente daquilo que é lembrado. Além disso, nos silêncios entrecortando as falas, nas expressões faciais e corporais, e no tom de voz, percebemos que os esquecimentos também fazem parte constitutiva das memórias individuais e coletivas.

\section{Esse é um dom que Deus me deu!}

Sobre seu trabalho como parteira, Dona Maria relata que começou aos vinte e cinco anos quando uma tia precisou de sua ajuda na hora do parto. Sozinhas tiveram que ajudar uma a outra nesse momento de trazer uma criança ao mundo. A partir de então, foi paulatinamente sendo acionada por outras mulheres quando ainda morava no município de Breves. Desde então, passou a desenvolver o que atualmente ela considera como um dom, um dom de Deus.

Ao longo dos tempos foi adquirindo mais experiência, conhecimento técnico e pela vivência como parteira. Atuante em termos de organização da categoria, fundou em 24 de agosto de 2000, juntamente com outras parteiras, a Associação de Parteiras Tradicionais de Melgaço (ATPM). Mas, devido ao falecimento de algumas mais velhas e pelo reduzido envolvimento das demais parteiras desse município, a ATPM está enfraquecida como entidade que as articula profissionalmente.

Ao descrever suas atividades demonstra inúmeros saberes sobre acompanhamento das parturientes para um parto mais tranquilo e conforme as preferências de local e modo de ter uma criança. Ela conhece como poucas pessoas a maneira de identificar o sexo biológico ainda nos 
primeiros meses de gestação. Sabe tratamentos para aliviar dores, contrações e tantas outras situações que envolvem gestação e parto.

A partir de 2000 participou de vários cursos e atividades de capacitação, inclusive em outros estados brasileiros. Ao falar desses cursos, Dona Maria foi ao seu quarto e retornou trazendo alguns dos equipamentos que foram adquiridos quando participou de cursos e treinamentos para aprimorar sua prática como parteira, incorporando outros conhecimentos médicos.

Segundo ela ainda nos relatou sobre o que considera como o marco inicial para o reconhecimento como parteira pela prefeitura foi o convite para participar de evento voltado para realização de parto e outros temas correlatos à saúde sexual e reprodutiva das mulheres. Assim ela descreve o convite para sua primeira participação naquilo que ela denomina como concurso:

- Foi no tempo do Casemiro. Foi em 2000 que nós fomos fazer o primeiro concurso. Eu estava em casa, era mais cedo que isso, era umas quatro horas, e o Judá chegou lá em casa. Não sei se a senhora conhece, ele trabalha com o pessoal da prefeitura. - Ele chegou em casa e disse: Ei Velha! (ele só me chama de velha).

- Velha não! Eu disse.

- Bora passear! Tu queira ou tu não queira, velha, tu vais passear. Vamos Dona Maria, a senhora vai passear, a senhora não fica. Olha! vai você, vai a Dona Doca, vai mais cinco ou seis parteiras, tantas quantas quiserem ir, quantas que puderem ir.

- Eu disse: quando é que a gente vai?

- Ele disse: é hoje!

- Mas, já? Vocês chamam em cima da hora

- Já velha! Ponha uma redinha numa sacola velha... Vamos sim, mais tarde venho te buscar.

- Aí perguntei pro velho: eu vou? Ele respondeu: vai, se é pro teu futuro.

- Fomos para Caxiuanã! Dona Bené também foi. Muito bonito Caxiuanã ${ }^{5}$.

- Já pensou fazer o útero da mulher com o barro? Já pensou fazer os ovários de barro?

Era umas trinta e pouca pessoas.

- Primeiro dia foi palestra, depois usaram barro para fazer o útero e ovários. Eu ficava só olhando, ficava só espiando.

- Todo mundo vinha espiar os meus, depois tiravam fotos e pediram para explicar. Algumas faziam só as xoxotas, mas não tinha nada dentro.

- Eu fiz o útero igual a um abacate e expliquei como funcionava. Eu olhava as outras e não falava nada. E dizia: estou aqui para aprender.

- Foram cinco dias. Cada um dos cinco dias eles faziam uma coisa.

Ao longo de sua narrativa sobre esta primeira atividade de capacitação, contou que os temas eram voltados para identificação da localização da cabeça da criança no útero da mãe, do tempo de gestação e da maneira como tratar uma mulher no momento do parto. Principalmente, a posição da mulher para ter neném. Nesse aspecto, assim ela detalhou o diálogo entre ela e a pessoa que atuava como instrutora:

\footnotetext{
${ }^{5}$ Caxiuanã é uma região do município de Melgaço onde funciona a Estação Científica Ferreira Pena, do Museu Paraense Emilio Goeldi.
} 
- E aí Dona Maria, qual sua posição para moça do primeiro filho?

- Então eu disse: Não tem posição, a posição quem procura é ela.

- Se ela quiser em pé, é em pé. Se ela quiser de cócora, é de cócora, se ela quiser sentada ela tem, se ela quiser deitada ela tem... quando chegar a hora não tem.

- Se tiver um bacio, primeiro eu coloco o bacio e a criança arria mais ligeiro porque ela fica apoiada pra baixo, não fica apoiada por cima.

- Quando a bolsa estoura a cama já está preparada. A criança vem e eu pego.

Não boto pedaço de tijolo porque maltrata isso aqui da coluna da mulher, aí fica uma mulher doente.

- Ela levanta, faço o asseio, vai deitar na cama ou na rede.

Após essa descrição ela lembra que no livro constam apenas fotos de suas ações neste curso. Segundo ela declarou isso ocorreu porque ela não "trabalha escandaloso" no momento do parto. Sua explicação foi enfatizada quando chamou atenção para o que ela apresenta como comentários da equipe do treinamento: "A senhora trabalha bem. A senhora é dom que Deus lhe deu. A senhora tem jeito, quando a criança sai a senhora já vai embrulhando e a mulher vai se desocupando e já vai fechando ela".

Dona Maria ponderou que além da mulher escolher a posição ideal para o parto, é importante cuidar dela logo após a chegada da criança. Segundo ela, após o asseio a mulher precisa ser fechada (referindo-se ao fato de estar com as pernas abertas para saída da criança). Para Dona Maria, "Se a mulher fica aberta, e se pegar um vento, já vai pegar uma doença”. Assim, os cuidados são detalhados em termos dos vários momentos do partejar.

O caminhar facilita o posicionamento ideal para a saída da criança, por isso Dona Maria aconselha que seja a mulher a escolher o momento e posição para o parto. Ela relata que em alguns ela caminha com a parturiente pelo quarto porque assim ela terá melhores condições para indicar se está, ou não, preparada para o nascimento da criança.

Nesses e em outros casos em que a mulher é iniciante, a calma e tranquilidade são essenciais para o trabalho dela e da parteira. Em suas lembranças ela traz casos de cuidados diferenciados dados a estas mulheres e indica como elemento central no trata com as iniciantes é o amor que tem em sua atividade como parteira: "Eu tenho muito amor quando vou fazer um parto. Quando é moça do primeiro filho eu rezo, eu agrado...Todo amor que a mulher tem o filho e ninguém ouve. Não se ouve barulho, só o choro da criança".

Assim, além das questões de conhecimentos adquiridos com a experiência em realizar diversos partos, é importante ressaltar que aspectos outros são incorporados nesta prática. Desse modo, o que indica Spivak (2010) acerca do falar de pessoas subalternizadas também necessita ser incorporado. O saber da medicina oficial/convencional não é de todo descartado pelas parteiras, mas 
o que dizer de profissionais que atuam em hospitais e maternidades acerca dos conhecimentos das parteiras? Será que elas são ouvidas e consideradas em seus saberes? Elas estão podendo efetivamente falar sobre o que adquiriram em termos de suas expertises baseadas em práticas empíricas? Essa questão sobre a subalternização de mulheres parteiras foi uma constante nessa pesquisa.

A problemática em torno da subalternização de mulheres parteiras já fora analisada em diversos trabalhos acadêmicos que demonstram como o tratar da saúde de mulheres foi sendo alterado pela chamada medicina oficial. Contudo, os saberes e práticas do partejar sustentado pela ancestralidade que as mulheres trazem em seus conhecimentos sobre si, sobre seus corpos, ainda é algo intenso e usual, principalmente em áreas onde o acesso à rede pública de saúde é precário, como é o caso de municípios do arquipélago do Marajó.

Diante dos desafios presentes no sistema oficial de saúde e por opção em adotar procedimentos com parteiras, as mulheres de Melgaço, principalmente aquelas em sua primeira gravidez ou com dificuldades ao longo dos meses de gestação, procuram o acompanhamento de outras mulheres para ter sua criança. Durante a realização da pesquisa de campo, Dona Maria foi procurada por uma jovem para certificar-se sobre o desenvolvimento de sua gravidez. Nessa oportunidade, e para manter a discrição desse momento, apenas uma mulher da equipe pode acompanhar o atendimento e a conversa que ocorreu em um dos quartos da casa.

Essa situação nos fez refletir sobre os interditos e as prescrições que envolvem uma pesquisa de campo, notadamente no âmbito da Antropologia, pois nem sempre somos aceitos nos grupos ou incorporados ao evento que é tema de investigação. Por questões de gênero, geração, situação do corpo, aspectos do próprio evento, entre outras, somos apresentados às limitações, a desafios e aos imponderáveis da pesquisa de campo. Por certo, o fato de estarmos numa equipe onde participam pessoas de diferentes perfis, contribuiu para avançarmos em determinadas circunstâncias e recuarmos em outras. De todo modo, trabalhar o tema sobre o parto já era sabido entre nós que em vários momentos desta pesquisa caberia a interlocução apenas entre mulheres.

A procura pelo atendimento com Dona Maria não significa que as mulheres não irão se interessar em serem atendidas também por profissionais da biomedicina. Assim como ocorre em outros casos, a complementariedade entre saberes e práticas é recorrente, ou seja, não há exclusão desse ou daquele modo de garantir um bom parto e saúde para a parturiente e suas crias. Mesmo após o parto há que se cuidar da vida com a atenção básica nos postos de saúde e com os procedimentos no resguardo.

Dona Maria relata, ainda, uma história de "criança encruada", ou seja, quando há demora no parto devido aos esforços físicos para o nascimento. Quando a espera pela hora do parto ocorre em 
mulheres que tem filho pela primeira vez é importante o uso do óleo doce (óleo de amêndoas) para massagear a barriga e para hidratar o canal vaginal.

Sobre o exame de toque ela nos descreve como fundamental para saber se é caso de parto natural ou se será parto com faca (maneira de definir parto cesariano). A partir de nossos questionamentos ela explica como procede: "Meto a mão na luva, passo o dedo no óleo de amêndoas, se varar o dedo é caso de parto para parteira, mas se apertou, não. Não tem quem faça, é caso de faca”. Ela conclui sua explicação sobre o exame de toque dizendo: "É muita ciência sim para parto de primeiro filho". Assim, se tiver espaço não precisa o parto Cesárea. Por isso, muitas são as mulheres que a procuram, para saberem se é caso de acompanhamento com parteiras ou caso de médico.

Outro tipo de parto que as parteiras não fazem se dá quando são gêmeos, ou seja, ela afirma que não fazem partos porque as crianças estão entrelaçadas. O risco desse tipo de parto decorre do fato de que "Gêmeos ninguém sabe se um braço está trançado no outro, ou se uma perna está trançada na outra". E conclui: "Nós parteiras não podemos fazer". Afirmar de modo categórico: "Se apertou e sentiu duas crianças não procure mais", e finaliza nossa série de conversas afirmando: "Esse foi o dom que Deus me deu! ".

\section{Conclusão}

As parteiras são mulheres possuidoras de conhecimentos ancestrais, de técnicas e do respeito dado por outras mulheres em suas comunidades. Aprenderam com suas mães e avós a reconhecer o poder da natureza e das divindades; a utilizar as ervas e as rezas; a exercer a caridade e irmandade ao estarem disponíveis a qualquer hora do dia ou noite; a ter paciência e esperar o momento certo para a mulher e a criança; a ensinar às mulheres como cuidarem de si mesmas.

Nesse contexto, a trajetória de Maria da Silva é exemplar, pois é parteira em Melgaço, embora tenha iniciado essa prática e oficio no município de Breves, foi naquele município que desenvolveu suas habilidades e conhecimentos sobre o ato de partejar.

Os estudos sobre mulheres e suas práticas relativas à sexualidade, reprodução, partejamento, concepção e contracepção, reforçam o viés antropológico naquilo que se refere à etnografia. Quando se inclui a possibilidade de aprender com elas, realizar atividades conjuntamente neste processo de investigação e buscar compreender suas lógicas, percepções e visões de mundo, dentre outras atividades.

A pesquisa sobre a trajetória de Dona Maria da Silva foi baseada em narrativa desenvolvida a partir da utilização de recurso audiovisual e nas ferramentas metodológicas da Antropologia. 
Estimulada pela ideia de realização de produção de um vídeo sobre sua biografia, e suas atividades como parteira em município do arquipélago do Marajó, Dona Maria apresentou a si mesma em narrativa que envolve a oralidade, lembranças de diferentes momentos de sua vida e descrição de saberes sobre o partejar. Embora tenha iniciado essa prática e oficio no município de Breves, foi no município de Melgaço que desenvolveu suas habilidades e conhecimentos referentes ao apoio no momento em que outra vida nasce um outro ser.

As questões que nos motivaram a realização dessa investigação permitiram refletir sobre a relevância de uma mulher parteira em município do arquipélago do Marajó. Pela sua luta em prol da vida, pelo reconhecimento de sua importância no atendimento de mulheres grávidas, inclusive pelo próprio poder executivo municipal, consideramos que mesmo com as condições de subalternidade, essa é uma mulher que pode falar. Sua fala é considerada e respeitada, portanto, é ouvida.

Por certo, essa prática ancestral, e marcada pelo conhecimento para além da medicina oficial, não é um resquício do passado que permanece em tempos atuais, e nem se trata de algo que só é buscado diante da ausência de leitos, equipamentos ou profissionais de saúde nos hospitais. Trata-se de uma escolha, principalmente para as mães inexperientes e para aquelas que tem nas parteiras, ora representadas nesse estudo pela trajetória de Dona Maria, o apoio que lhes permite o protagonismo no momento do parto. Por certo, muitas são as mulheres que trazem consigo as lembranças dos conhecimentos ancestrais de outras mulheres nas situações relativas ao parto, às suas crias ainda recém-nascidas e aos cuidados consigo durante e após a gestação.

\section{Referências}

CANEN, Ana; XAVIER, Libânia Nacif. Multiculturalismo, memória e história da educação brasileira: Reflexões a partir do olhar de uma educadora alemã no Brasil imperial. In: MIGNOT, Ana Chrystina Venancio; BASTOS, Maria Helena Camara; CUNHA, Maria Teresa Santos (Org.) Refúgios do eu: Educação, história, escrita autobiográfica. Florianópolis: Mulheres, 2000. 63-80.

FLEISCHER, Soraya. Parteiras, buchudas e aperreios: uma etnografia do atendimento obstétrico não oficial em Melgaço, Pará. Belém: Editora Pakatatu/EDUNISC, 2011.

FREITAS, Sonia Maria de. História oral: possibilidades e procedimentos. São Paulo: Humanitas/Imprensa Oficial de São Paulo, 2002. 143 p.

HALBWACHS, Maurice. A memória coletiva. Trad. Beatriz Sidou. São Paulo: Centauro, 2003. 
JANNOTTI, Maria de Lourdes Mônaco; PAULA, Ricardo Zimbrão de. História oral: uma utopia? In: GARRIDO, J. del A. As fontes orais na pesquisa histórica: uma contribuição ao debate. Revista Brasileira de História. 25/26 - Memória, história, historiografia - Dossiê ensino de história. São Paulo: ANPUH, Marco Zero/ SCT/CNPq/FINEP, p. 9-14, 1998.

PEDRO, Maria Joana. As representações do corpo feminino nas práticas contraceptivas, abortivas e no infanticídio - Século XX. In: MATOS, Maria Izilda; SOIHET, Rachel (Org.) O corpo feminino em debate. São Paulo: Editora Unesp, 2003. p. 157-176

RIBEIRO, José da Silva. Antropologia visual, práticas antigas e novas perspectivas de investigação. Revista de Antropologia, São Paulo, USP, v. 48 n. 2, 2005.

SPIVAK, Gayatri Chakravory. Pode o Subalterno Falar? Belo Horizonte: UFMG, 2010.

WALSH, Catherine. Interculturalidade Crítica e Pedagogia Decolonial: In-surgir, re-existir e reviver. CANDAU, Vera Maria (Org.) Educação Intercultural na América Latina: entre concepções, tensões e proposta. Rio de Janeiro: Sete Letras, 2009. p.12-43 